\title{
RESULTADOS COMPARADOS DE UMA CAMPANHA DE PROSPECÇÃO GEOFÍSICA COMPLETA NA PLANÍCIE DA VARGEM, ÁGUAS DA PRATA, SP
}

\author{
A. DAVINO e P. TALTASSE \\ Instituto de Geociências e Astronomia, USP
}

\begin{abstract}
The Vargem plain, located in the right bank of the Quartéis river, near Águas da Prata town in the State of São Paulo, corresponds to a structural graben emplaced in the crystalline basement, of Pre-Cambrian age. It is filled up with fluvial deposits. It is not more than a marginal accident as it occurs frequently on the board of the volcanic complexes.

This alluvional valley contains a water-table fed by small irrigation channels derived from the Quartéis river. In order to evaluate with maximum accuracy the importance of the phreatic water reserves the determination of the depth and the contact shape between alluvions and crystalline rocks needed the application of the three classical geophysical methods: resistivity, seismic and magnetometry.

Each one of these methods gave informations of the geometry of the geological contact and of the local nature of the basement rocks.

According to informations collected at the shallow wells located in this plain, it appears that, from the point of view of the geometry of the geological contact, the seismic method shows the best results.
\end{abstract}

INTRODUÇÃo A planície aluvionar da Vargem (Fig. 1), situada à margem direita do rio dos Quartéis, a jusante da cidade de Águas da Prata, SP, corresponde estruturalmente a um graben de direção NO-SE, encravado no embasamento cristalino pré-cambriano e preenchido por depósitos fluviais.

Esse acidente tectônico acompanha a borda sul do complexo alcalino de Poços de Caldas. Trata-se de um acidente liminar clássico, nos contatos de dois conjuntos geotectônicos diferentes: ao norte, o maciço vulcânico e, ao sul, o embasamento cristalino.

A planície aluvionar da Vargem contém um lençol aqüífero importante alimentado pela pluviosidade ( $1450 \mathrm{~mm} / \mathrm{ano}$ ), pela contribuição dos lençóis freáticos das lateritas dos terrenos cristalinos que a bordejam e, ainda, pelos canais artificiais de irrigação, derivados do rio dos Quartéis, os quais cobrem a Vargem, formando uma rede cerrada.

A alimentação artificial do lençol é mais importante que a alimentação natural. A drenagem desse lençol é efetuada normalmente a jusante no contato da Vargem com o embasamento cristalino e envolve fontes importantes que bordejam a margem direita do rio dos Quartéis.

A fim de cubar o volume da reserva aqüifera representado por esse lençol, cuja rocha-reservatório apresenta coeficiente de permeabilidade de $5 \cdot 10^{-3} \mathrm{~cm} / \mathrm{s}$ e porosidade eficaz de $14 \%$, valores medidos em diversos pontos (sendo a vazão de alimentação praticamente constante), era necessário determinar a configuração do contato aluvião/embasamento cristalino e, por conseqüência, a geometria do aqüifero.

Para obter uma resposta satisfatória aos problemas hidrogeológicos foram realizados os seguintes estudos geofisicos detalhados:
a) Eletrorresistividade
b) Sísmica
c) Magnetometria 


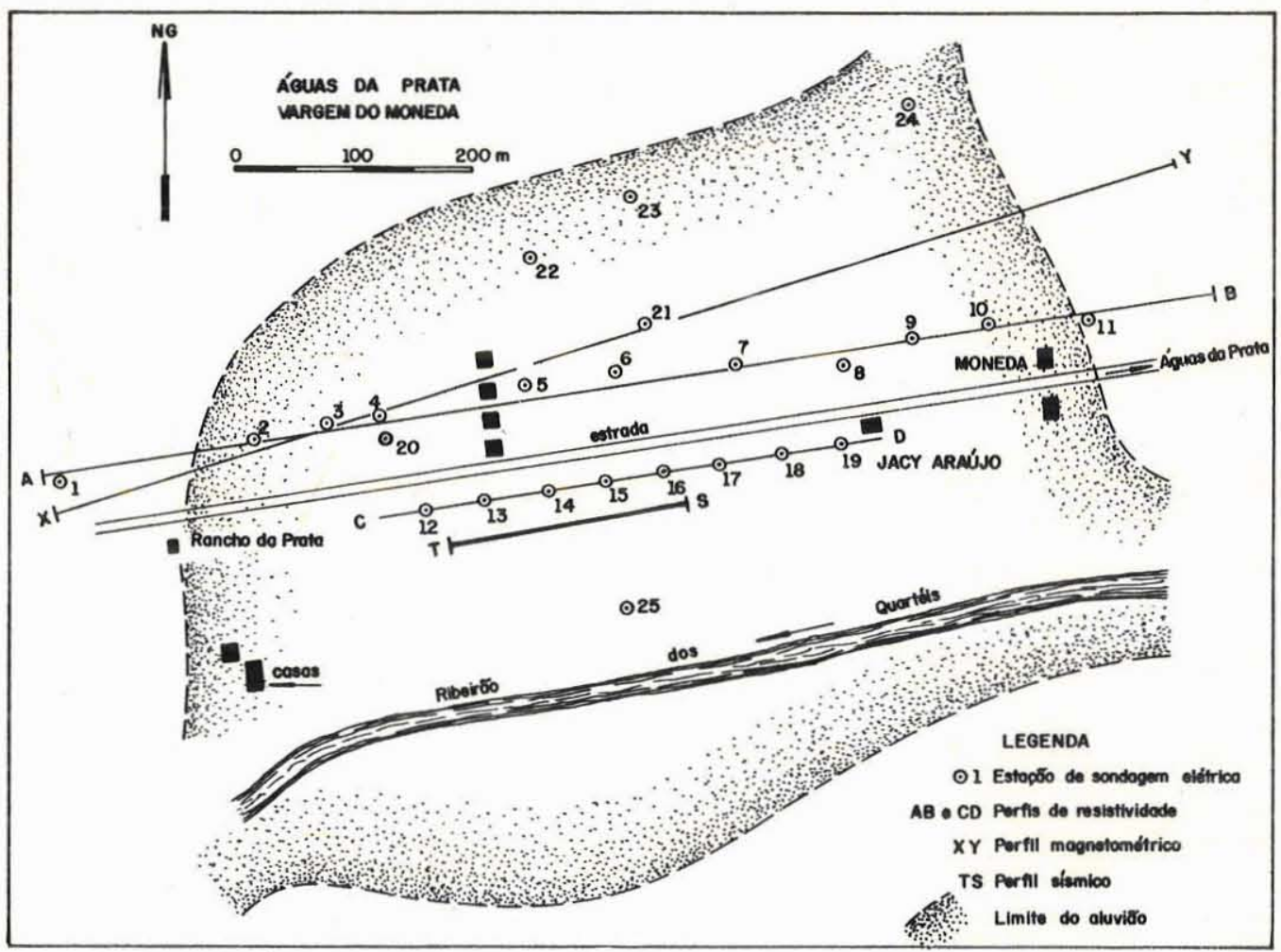

Figura 1 - Área prospectada em Águas da Prata

Eletrorresistividade A eletrorresistividade é o método geofísico mais empregado no estudo dos problemas hidrogeológicos, seja na pesquisa direta da água subterrânea, uma vez que o parâmetro de resistividade está ligado à quantidade e à qualidade da água, seja na pesquisa indireta, isto é, na pesquisa que visa ao estabelecimento da geometria do aqüifero.

A determinação das dimensões de aluviões é um exemplo clássico de aplicação do método de eletrorresistividade em problemas hidrogeológicos.

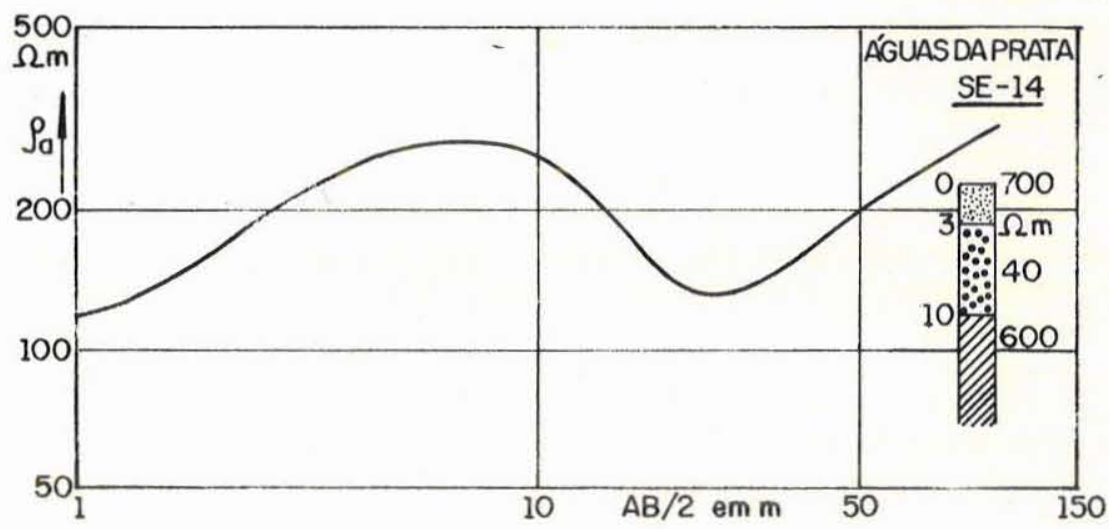

Figura 2 - Sondagem elétrica número 14 
Foram executadas 24 sondagens elétricas na área pesquisada (veja a Fig. 1). Cada sondagem elétrica pode ser interpretada em termos da espessura e da resistividade dos estratos atravessados.

A Fig. 2 representa a sondagem elétrica n. ${ }^{\circ} 14$ (veja localização na Fig. 1). É uma curva que representa a resistividade aparente em função da metade da distância entre os elétrodos de corrente, normalmente designados por A e B. A interpretação dessa curva fornece os dados representados no perfil à direita da figura.

De 0 a 3 metros de profundidade: material aluvionar, com blocos decimétricos (conforme observação de campo) acima do nível estático; a resistividade desse estrato é da ordem de $700 \mathrm{ohm} \cdot \mathrm{m}$.

De 3 a 10 metros, trata-se provavelmente do mesmo material, talvez um pouco mais argiloso, abaixo do nível estático. Sua resistividade é de cerca de $40 \mathrm{ohm} \cdot \mathrm{m}$.

Abaixo de 10 metros de profundidade, encontra-se o embasamento cristalino, com resistividade de $600 \mathrm{ohm} \cdot \mathrm{m}$, valor esse indicativo de que o embasamento rochoso deve se apresentar parcialmente alterado de, no mínimo, uma dezena de metros.

A interpretação dessas 24 sondagens elétricas forneceu inicialmente uma idéia geral da geometria do aluvião. Para melhor visualizar essa geometria foram traçados perfis de resistividade aparente (perfis $\mathrm{AB}$ e $\mathrm{CD}$, na Fig. 1). Esses perfis foram obtidos a partir dos dados das sondagens elétricas e podem ser vistos na Fig. 3. Foram utilizados os valores de resistividade aparente correspondentes a $A B=100 \mathrm{~m}$ e $A B=200 \mathrm{~m}$. Os perfis, interpretados e comparados entre si, permitem esboçar uma seção do terreno onde as profundidades são fornecidas pelas sondagens elétricas.

Sísmica As sondagens elétricas, na maioria das vezes, conduzem a sérias indeterminações. A interpretação exige uma longa experiência e bom conhecimento da estrutura geológica da área investigada. Além disso, uma série de medidas quase idênticas conduz a estruturas completamente diferentes.

Um trabalho de sísmica de refração geralmente consegue levantar as indeterminações dos dados de resistividade. Na Fig. 4 estão representados os resultados do perfil de refração sísmica realizado ao longo da direção TS. Foram realizados 5 tiros sísmicos com um equipamento R-4 da SIE, de 12 canais.

Os resultados do trabalho de sísmica (Fig. 4) indicaram que a espessura do aluvião é da ordem de 10 metros, mergulhando suavemente para o mesmo eixo indicado pelos perfis de resistividade aparente.

Magnetometria Um único perfil magnetométrico levantado na área da Vargem (veja a Fig. 1, perfil XY) indicou anomalias da ordem de 400 gamas, o que sugere que o substrato da planície aluvionar da Vargem não é constituído apenas pelo gnaisse que aflora a oeste desse local. Situada à margem de um maciço alcalino e em parte envolvendo rochas basálticas da bacia do Paraná, não é dificil imaginar que as fraturas e falhas abertas no embasamento estejam preenchidas por material magmático magnético ou que envolvam o deslocamento de diabásios da bacia do Paraná.

CONCLUSÕES 1) A planície aluvionar da Vargem, em Águas da Prata, corresponde estruturalmente a um graben encravado no embasamento cristalino, na borda sul do complexo cristalino de Poços de Caldas.

2) O lençol aqüifero desse aluvião é alimentado parte pela pluviosidade e parte pelos canais artificiais que cortam a região. 


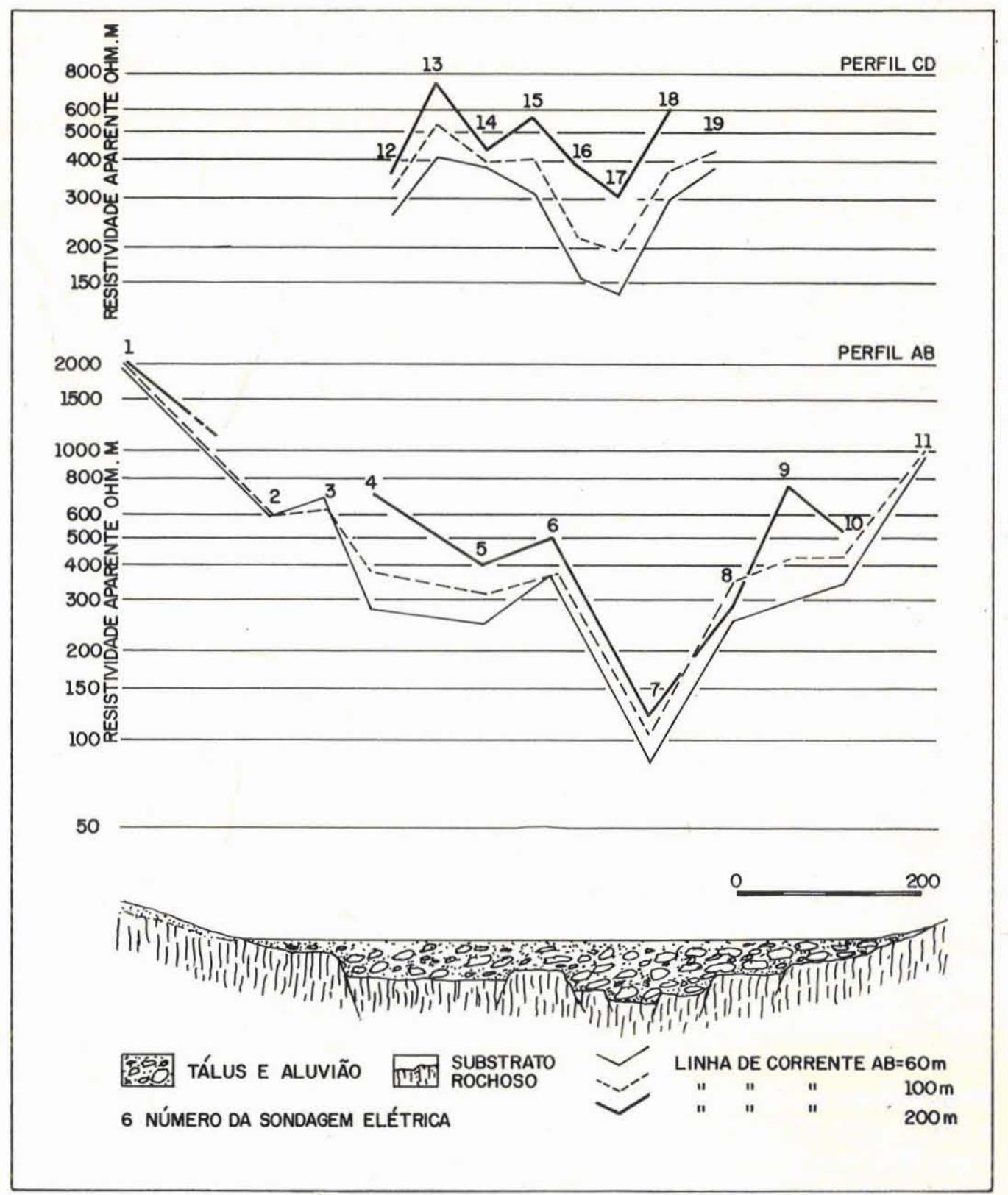

Figura 3 - Sondagens elétricas

3) Uma idéia clara da geometria do aqüífero pôde ser obtida por um levantamento eletrossísmico. A profundidade média gira em torno de 10 metros e a máxima, de 15 metros.

4) O substrato rochoso é, provavelmente, cortado por rochas magmáticas básicas, conforme indica o perfil magnetométrico. 


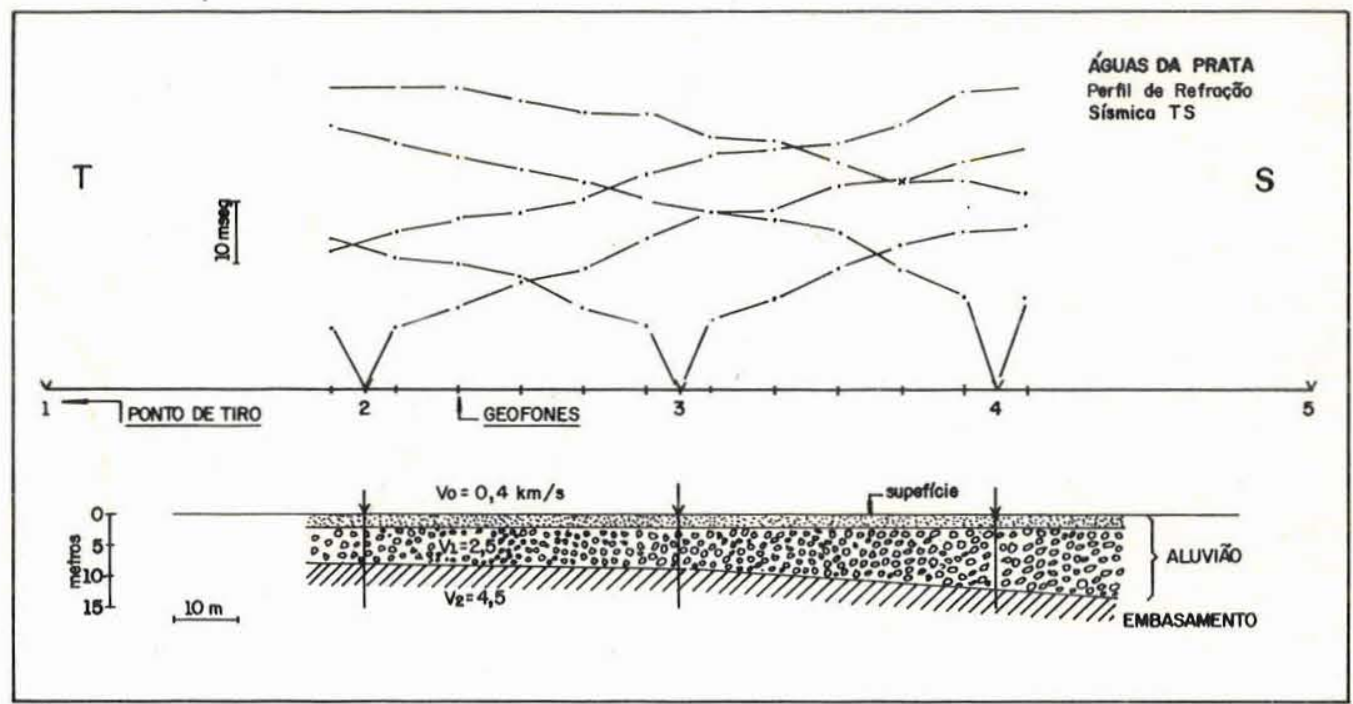

Figura 4 - Perfil de refração sísmica

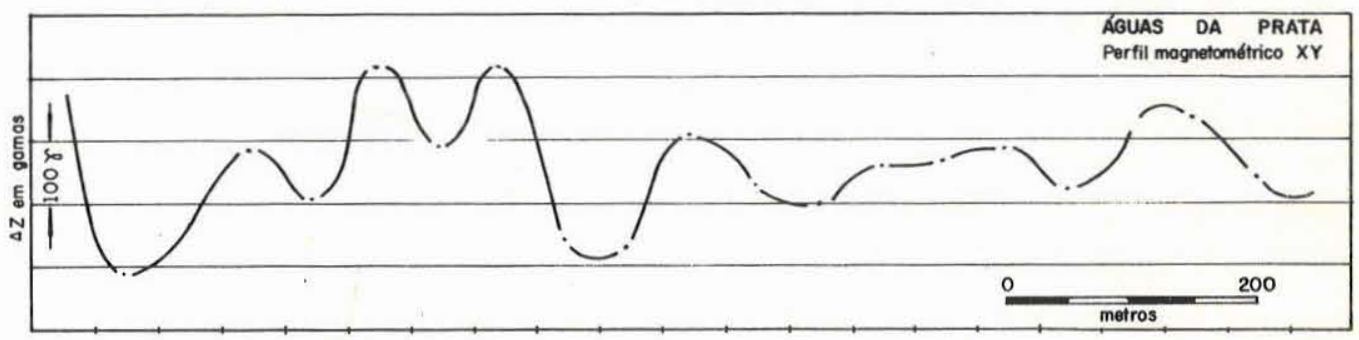

Figura 5 - Perfil magnetométrico XY

Agradecimentos Os autores agradecem ao Geólogo Dr. Luiz Francisco Rielli Saragiotto, Diretor da Divisão de Minas e Geologia Aplicada do IPT, pelo apoio prestadỏ ao estágio dos alunos de Geologia da USP em Águas da Prata, o que permitiu a realização deste trabalho. São gratos igualmente ao Geólogo Victor L. O. Meyer pela ajuda prestada durante os trabalhos de campo.

\section{BIBLIOGRAFIA}

TALTASSE, P. - 1968 - As fácies hidroquímicas no Estado de São Paulo. Anais do XXII Congresso Brasileiro de Geologia, pp. 263-266. Belo Horizonte.

TALTASSE, P. e DAVINO, A. - 1968 - Exemplos de aplicação de métodos geofísicos em estudos geo-hidrológicos. Anais do XXII Congresso Brasileiro de Geologia, pp. 267-269. Belo Horizonte. 